\title{
Hochgeehrter Herr Geheimrath!
}

Einige Ihrer Schüler haben die Feier Ihres siebenzigsten Geburtstages nicht vorübergehen lassen wollen, ohne Ihnen im eigenen Namen und im Namen ihrer zahlreichen Genossen ein Zeichen unwandelbarer Treue und aufrichtiger Verehrung zu geben, und bringen Ihnen hiermit eine Reihe wissenschaftlicher Abhandlungen dar, welche bezengen sollen, dass der Geist Ihrer Lehre und Forschung, den Sie durch Ihr beredtes Wort und strenges Vorbild in ihre Seelen gepflanzt, Früchte gezeitigt habe, welche Sie nicht unwürdig befinden mögen.

Als einer Ihrer ältesten Schüler, der Ihre Wege zu wandeln bemüht war und auf diesen, was er nach dem Masse seines Könnens und der Lage der Verhältnisse an philologischer Arbeit zu leisten vermochte, Ihnen vor anderen zu danken hat, hätte ich mich gerne in der Weise der Darbringenden bethätigen wollen. Aber Sie wissen, dass ich seit mehreren Jahren andere Sorgen und Mühen auf mich genommen habe und kaum in der Lage wäre, unter dem Drucke zeitraubender Geschäfte etwas für den Zweck zu schaffen, was den Empfänger und den Geber befriedigen könnte.

Aber die zu Ihrer Ehrung Vereinigten wollten mich doch zu Worte kommen lassen und waren der Meinung, dass ich eine Art einleitenden Kommentars zu dieser Festschrift zu verfassen nicht ganz ungeeignet wäre. Keine Aufforderung konnte mir willkommener sein. 
Befand ich mich ja unter der Zahl der ersten Hörer, die Sie als jüngster Lehrer der Wiener Universität in jugendlicher Frische durch den Zauber Ihres begeisterten Vortrages gefangen nahmen und zugleich in dem von Ihnen geleiteten Seminare mit fester Hand an Zucht und Einfachheit der Gedanken gewöhnten. Bald darauf war es mir vergönnt, durch einige Jahre als Kollege an Ihrer Seite zu wirken. Als Sie aber leider zu früh der Wiener Universität genommen und auf den Lehrstuhl berufen waren, den vor Thnen die grössten Meister unseres Faches inne hatten, und welchen Sie nunmehr fast durch ein Menschenalter ruhmvoll bekleiden, da lockerte die örtliche Trennung in nichts die geistigen Beziehungen, und ich verfolgte lernend und bewundernd Ihre rastlose und an Erfolgen reiche wissenschaftliche Thätigkeit, die weit über den engeren Kreis Ihrer Hörerschaft von eingreifendem Einfluss war.

Indem ich Sie also im Namen Ihrer Verehrer bei diesem seltenen Feste begrüssen und feiern darf, kann ich es mir erlassen, eine Liste Ihrer Publikationen zusammenzutragen, um an ihr das weite Feld Ihrer Forschung abzustecken und an der Art, wie Sie in oft unscheinbarer Weise die Worte eines Schriftstellers richtigstellen oder erklären, Ihre die entlegensten Gebiete der Altertumswissenschaft durchdringende und beherrschende Gelehrsamkeit zu rühmen, oder im einzelnen darzulegen, wie Sie über das klassische Altertum hinaus Ihre historischen Forschungen erstreckt und an hervorragenden Persönlichkeiten der Renaissance oder der neueren Literatur die geistigen Strömungen anderer den Philologen schwer zugänglicher Epochen in ihren intimsten Zügen erfasst und mit lebendiger Anschaulichkeit dargestellt haben.

Ich glaube damit in Ihrem Sinne zu verfahren, weil ich nicht rühmen will, was Sie selbst nie als rühmenswert erkannten; denn mit Gelehrsamkeit zu prunken haben Sie stets verschmäht und Vielschreiberei weder selbst erstrebt noch in Ihren Schülern gezüchtet. Schreiben sollte nur der, welcher besass, was als Gewinn neuer Erkenntnis der Mitteilung an andere wert schien. Ihr reiches Forscherglück freilich liess Sie solche strenge Selbstzucht leichter wahren. 
Und doch möchte ich auf ein Arbeitsfeld besonders hinweisen, auf eines der schwierigsten und zugleich reizvollsten, das Sie mit jugendlichem Wagemut betraten und sofort mit gereifter Besonnenheit $\mathrm{zu}$ bestellen verstanden haben. Ich meine die Trümmer zerstörter Werke der alten römischen Dichtkunst, deren Herstellung neben ausgedehnter Belesenheit genaue Bekanntschaft mit der Eigenart einer vielverzweigten Leberlieferung, Vertrautheit nicht bloss mit dem Sprachgebrauche und dem Stile des betreffenden Schriftstellers, sondern auch jeder Quelle, der ein Bruchstück zu entnehmen ist, Geschicklichkeit, die entlegensten Notizen zu verbinden und richtig zu verwerten, erfindsame Heilung mannigfacher Verderbnisse der Ueberlieferung, sorgfältiges Abwägen des Möglichen und Wahrscheinlichen erheischt. Sie haben die für das Gelingen solcher Arbeit erforderlichen Bedingungen in seltenem Masse in sich vereinigt und dabei zugleich eine Tugend $\mathrm{zu}$ bewähren begonnen, die Sie in Ihren späteren Werken zu vollkommenster Reife entwickelt haben, eime Tugend, auf welcher der eigenartige Vorzug Ihrer gesamten philologischen Thätigkeit beruht, und welche zugleich der Philologie unserer Zeit eine festere Richtung zu geben geeignet war.

Als man, noch leicht befriedigt, in sinnreichen und glücklichen Vermutungen schwelgte, um üher eine ungewöhnliche oder nicht sofort begreifliche Textesstelle hinwegzukommen, haben Sie solchen Einfällen des Augenblicks misstrauen, schielende Erfindungen zurückweisen, die verachtete L'eberlieferung prüfen und verteidigen gelehrt.

Der Erfolg dieser Methode war nicht bloss die Rettung der Texte vor entstellenden Veränderungen; ihr weit wichtigerer Ertrag war die sich dadurch ergebende Erkenntnis dessen, was der Schriftsteller gedacht und gewollt, sowie das Verständnis der Form, die er seinen Gedanken gegeben hat. Wie ein Gemälde Tizians oder Raffaels, von der Tünche übermalender Korrekturen befreit, wie neugeboren mit der vollen Frische seiner Farben auf unser Auge wirkt, so haben wir aus Ihrer Hand die Werke des Horaz und Tibull, des Sophokles, Euripides und anderer Autoren empfangen, 
die uns nun wieder bis in die unscheinbarsten Züge das Gepräge ihrer Meister zeigen. Freilich wird das nicht jedem und keinem ohne heisses Bemühen gelingen; es setzt liebevolle Vertiefung in den Sprachgebrauch, welche weder Grammatik noch Lexikon noch die emsigste Statistik zu vermitteln vermag, feine Empfindung für die Form, verständnisvolles Eingehen in die Eigentümlichkeiten des Schriftstellers, ein Miterleben und Mitempfinden des vom Schriftsteller Erlebten und Empfundenen, also Vorzüge voraus, welche durch unablässige Uebung zwar geschärft, aber durch sie allein nicht erworben werden.

Im einzelnen mag das auf diesem Wege mühevoll Erreíchte gering erscheinen. Das Einzelne vereinigt aber führt zu dem hohen Endziel philologischer Kleinarbeit, die antike Litteratur wieder in ihrer ursprünglichen Form und nach ihrem vollen Gehalt zu besitzen und zu geniessen.

Der Gewinn dieser von Ihnen in unvergleichlicher Weise geübten Methode philologischer Kritik und Exegese ist von vorbildlicher Bedeutung für jede Art von Philologie, ob sich diese mit lateinischen oder griechischen, romanischen oder deutschen, slavischen oder indischen Texten befasse, sie bereitet jeder historischen Forschung den Boden und legt ihr den Stoff geläutert und gesichtet vor. Zugleich ist ihr Wert ein ethischer und erziehender, indem durch sie auch dem blöden Spötter, der die Philologie als eitel Wortklauberei oder als Tummelplatz müssiger, bestenfalls witziger Einfälle verachtet oder, so weit sie der Schule angehört, sie als ein Erbübel zu beklagen geneigt ist, der Ernst wissenschaftlicher Forschung und die Bethätigung künstlerischen Empfindens ersichtlich werden kann, und indem sie durch Erkenntnis der Eigenart und durch das nachempfindende Siehhineinleben in die Persönlichkeiten alter Schriftsteller wie kaum ein an anderen Stoffen geübtes Unterrichtsverfahren den Geist der Lernenden befruchtet und bereichert und ihnen ein tieferes Verständnis der gesamten Cultur der Gegenwart zu eröffnen vermag.

Die Erfüllung dieser der klassischen Philologie obliegenden Aufgaben ist zugleich ihre wirksamste Verteidigung, und somit 
haben Sie allen denen, welche Sie in Ihrem Geiste Philologie treiben gelehrt, auch eine starke Waffe in die Hand gegeben, um die heute lauter und ungestümer vordrängenden Widersacher dieser Wissenschaft abzuwehren, und Ihre Schüler für die Erfüllung aller öffentlichen Pflichten in der Schule auf das trefflichste ausgerüstet.

In wie hohem Grade Ihnen dies gelungen ist, dafür darf ich auf die grossen und dauernden Erfolge hinweisen, die Ihr kurzes Wirken in 0esterreich in allen Ländern unseres vielsprachigen Reiches an Hoch- und Mittelschulen zurückgelassen hat. Dass Ihnen aber Thre alte Heimat, der Sie Oesterreich ungerne zurückgab, und welcher Sie in voller Manneskraft hingebend und unermüdlich gedient haben, zu nicht geringerem Danke verpflichtet ist, kann auch der Fernstehende zu behaupten sich für berechtigt halten. Das lehrt ihn ein flüchtiger Blick auf die Zahl und die Bedeutung Ihrer allerorts wirkenden Schüler. Dafür bürgt die Hochschätzung Ihrer Kollegen an der Universität und in der Akademie, welche mit ehrendem Vertrauen die schwierigsten Aufgaben stets in Ihre Hand gelegt haben.

Empfangen Sie darum von Ihren Schülern und Verehrern in Deutschland und Oesterreich die aufrichtigsten Glückwünsche an dem heutigen Festtage, in freudigerer Stimmung dargebracht von den einen, die sich freuen dürfen, Sie zu besitzen, mit nicht geringerer Herzlichkeit von den anderen, die Sie einst besessen und nie ganz verloren haben.

\section{Wilhelm von Hartel.}

